\title{
Nonparturitional exposure to donor placenta and placentophagia after lateral hypothalamic lesions in rats
}

\author{
MICHAEL NOONAN and MARK B. KRISTAL \\ State University of New York, Buffalo, New York 14226
}

\begin{abstract}
Previous research has shown that parturitionally experienced rats with lateral hypothalamic (LH) lesions that rendered them otherwise aphagic, still ate placenta when it was delivered (pregnant subjects) or presented (nonpregnant subjects). Subsequent studies have shown that some virgin rats are spontaneously attracted to donor placenta, whereas the others clearly avoid it. The present study was designed to demonstrate that the sparing of placentophagia after LH lesions observed in the earlier study was not due merely to the previous ingestion of placenta, per se, or to inadvertent selection for spontaneous placentophages. Virgin placentophages were allowed to consume donor placenta; some were then bred. Prior to parturition or after an equivalent time interval, LH lesions were produced through indwelling electrodes. The next day, not only were the animals with properly placed lesions aphagic to a cookie/milk mash, but none ate delivered or presented placenta.
\end{abstract}

During parturition, most placental mammalian mothers ingest the delivered afterbirth, which consists mainly of the placenta, amnion, and fetal fluids. This phenomenon, placentophagia, might be considered as a maternal behavior or as an ingestive behavior. Kristal (1973) investigated the extent to which placentophagia was controlled by hypothalamic mechanisms that are involved in the regulation of homeostatic feeding, by examining the effect on placentophagia of lateral hypothalamic (LH) lesions. He found that lesions produced through indwelling electrodes, which produced aphagia to a palatable liquid diet, and which produced adipsia, also eliminated placentophagia in rats giving birth for the first time, and in nonpregnant nulliparae presented with foster placenta. Placentophagia was not eliminated, however, in otherwise aphagic and adipsic rats that were giving birth for the second time, or that were nonpregnant multiparae presented with foster placenta. The conclusion drawn from that study was that experience with placenta (acquired during a previous parturition) prevented placentophagia from being eliminated by the effects on ingestion of destruction of the LH.

Subsequent research on placentophagia has shown that a proportion of virgin rats (Kristal \& Graber, 1976) and mice (Kristal \& Eleftheriou, 1975; Kristal \& Williams, 1973) are strongly attracted to placenta (obtained surgically from donors) and will eat it, whereas the rest avoid the foster placenta, withdraw from it,

This research was supported by NSF Grant BNS76-04316, awarded to Mark B. Kristal. Reprints may be obtained from Mark B. Kristal, Department of Psychology, State University of New York at Buffalo, 4230 Ridge Lea Road, Buffalo, New York 14226. and will not eat it even after repeated presentations. Furthermore, the effect of parturitional experience is strong, in that some virgin noneaters become nonpregnant eaters after eating placenta during delivery (which virtually all mother rats and mice do), so that the proportion of a sample of nonpregnant primiparae that eat placenta is greater than that of a sample of virgins, and the proportion of placentaphages in a sample of nonpregnant multiparae is greater than that of the sample of primiparae (Kristal \& Graber, 1976; Kristal \& Williams, 1973).

At the time the Kristal (1973) study on the effect of LH lesions on placentophagia was conducted, the response of nonpregnant rats to placenta had not been examined in great detail. Therefore, since the subjects had not been pretested as virgins, the baseline attitude toward placenta of those subjects was unknown. It was assumed that since both pregnant and nonpregnant primiparae with LH lesions showed sparing of placentophagia, experience with placenta acquired during the previous parturition afforded the protection. It now seems possible that virgin placentophages, afforded the opportunity to eat foster placenta, might also acquire sufficient experience with placentophagia to prevent its elimination by LH lesions. If virgins so treated still manifested placentophagia but were otherwise aphagic and adipsic, one might conclude that parturitional experience, per se, is not as critical as was earlier supposed, and that either (1) placenta is extraordinarily attractive to virgin placentophages that have experienced it, or (2) placentophages are somehow wired differently than nonplacentophages. If placentophagia is eliminated by $\mathrm{LH}$ lesions in virgin placentophages that have ingested as much placenta as a parturient rat, one could conclude that there is something specific about experience with 
placenta acquired during delivery, as was hypothesized earlier (Kristal, 1973).

\section{METHOD}

\section{Subjects}

Twenty-four female hooded rats (Charles River Breeding Laboratories), 4-7 months old, and weighing 250-310 g, were used. Normal estrous cyclicity was verified with daily vaginal smears. Except when otherwise noted, food (Charles River Rat/ Mouse/Hamster Formula) and water were available ad lib. Each rat was housed in a $24 \times 19 \times 18 \mathrm{~cm}$ wire-mesh cage. The colony was maintained on a 14-h on/10-h-off daylight cycle, with the on phase beginning at 6:00 a.m. (EST).

\section{Procedure}

Placentophagia pretest. After verification of normal cyclicity, each female was given a pretest to determine whether she was a placentophage or a nonplacentophage. Each rat, after $2 \mathrm{~h}$ of food deprivation and 15 min of water deprivation, was presented with one donor placenta in an untipable glass dish. Donor placenta was obtained surgically from $\mathrm{CO}_{2}$-killed primiparae on Day 21 of pregnancy. The placentas were then frozen, along with a few drops of normal saline, at $-20^{\circ} \mathrm{C}$, and stored until needed. At that time, the placentas were rapidly thawed and warmed to about $35^{\circ} \mathrm{C}$, and presented to the subjects. The subject was given a 15 -min exposure to the dish of placenta. This procedure was repeated on 3 consecutive days, or until the rat ate the placenta. Placentophages are most likely to eat placenta on the first exposure; rats that have not eaten by the end of the third exposure are not likely to eat placenta at all (Kristal \& Graber, 1976). Only rats determined to be placentophages in the pretest were used in the present study.

Surgery. Two to 3 weeks after the pretest, each rat underwent stereotaxic implantation of chronic LH electrodes, under sodium pentobarbital anesthesia (Diabutal; $4 \mathrm{mg} / 100 \mathrm{~g}$ body weight, IP), preceded by an injection of atropine sulfate $(.08 \mathrm{mg} / 100 \mathrm{~g}$ body weight, IP). A pair of Epoxylite-insulated, .012 -in. stainless steel electrodes (with the tips clipped off) was inserted into the leveled head (Kristal, 1973) according to the following coordinates: $2.5 \mathrm{~mm}$ posterior to bregma, $\pm 1.8 \mathrm{~mm}$ lateral to the midline sinus, and $9.0 \mathrm{~mm}$ down from the surface of the skull. Four No. 0-80, 1/8-in stainless steel screws were used as anchors for the acrylic dental cement used to fasten the electrodes in place. The scalp was sutured around the dental cement and crystaliine sulfathiozole was sprinkled on the incision.

Procedure. Each rat was allowed 1 week of recovery from surgery before the vaginal smearing procedure was resumed. When the rat was again determined bo be cycling normally, she was fed five donor placentas presented all at once under conditions similar to the pretest. All of the rats ate all five placentas. Each rat was then randomly assigned to one of three groups: Sham (nonlesioned-nonpregnant), lesioned-nonpregnant, or lesioned-pregnant.

Approximately 1 week after ingesting the five placentas, each rat in the pregnant groups was time bred. The day on which a sperm plug or sperm in the vaginal smear was detected was considered Day 1 of pregnancy. On Day 19 of pregnancy, or after an equivalent time interval, each rat was presented with about $2.5 \mathrm{ml}$ of a highly palatable mash consisting of crushed chocolate chip cookies mixed with evaporated milk. The mash was presented in small, untipable glass dishes. All subjects ate all of the mash within 1 or $2 \mathrm{~min}$.

At noon 3 days later (on Day 22 of pregnancy, for the pregnant rats), each rat in the lesion groups was anesthetized lightly with ether, and $2.0 \mathrm{~mA}$ dc were passed between each indwelling LH electrode and a rectal cathode for $10 \mathrm{sec}$. Nonlesioned animals received the same treatment throughout the experiment, except that at this point, no current was passed through the electrodes. Afterwards, each rat was placed in a $45 \times 19 \times 25 \mathrm{~cm}$ plastic cage containing three paper towels; the lid contained a food hopper and a water bottle, the contents of which had been measured.

At noon the next day (all the pregnant subjects having given birth) the parturient rats were observed for maternal behavior and for the presence of placenta, and all subjects were presented for $15 \mathrm{~min}$ with a dish containing five donor placentas to test for placentophagia, and presented for $15 \mathrm{~min}$ with a dish of cookie mash to test for aphagia. After testing was completed, each rat was anesthetized and perfused with normal saline followed by $10 \%$ formalin. The brains were then removed, fixed in formalin, cut at $30 \mu$ on a freezing microtome, and stained with cresyl violet.

\section{RESULTS AND DISCUSSION}

Each experimental subject was classified as having adequate LH lesions both by showing aphagia to the cookie mash and by histological verification of the lesions, which was performed in ignorance of the behavioral results. There was perfect agreement between the behavioral and histological decisions. Rats that were determined not to have adequate LH lesions were placed in a lesion-control group. All but one of the aphagic rats was also adipsic. A diagrammatic summary of the lesion damage in the experimental rats is presented in Figure 1.

In regard to placentophagia, the number of rats that ate placenta that was either in a dish (nonpregnant subjects) or delivered normally (pregnant subjects) is presented in Table 1. Except for one rat who ate only half of the total number of delivered placentas, the lesioned rats ate none of the delivered or presented placentas. When the data from the lesioned animals were compared with those of the nonlesioned and lesioncontrol animals, for placentophagia and for aphagia to cookie mash, the resulting Fisther exact-probability tests indicated that for each, $\mathrm{p}<.0001$.

Clearly, in contrast to the effect of acquiring experi-

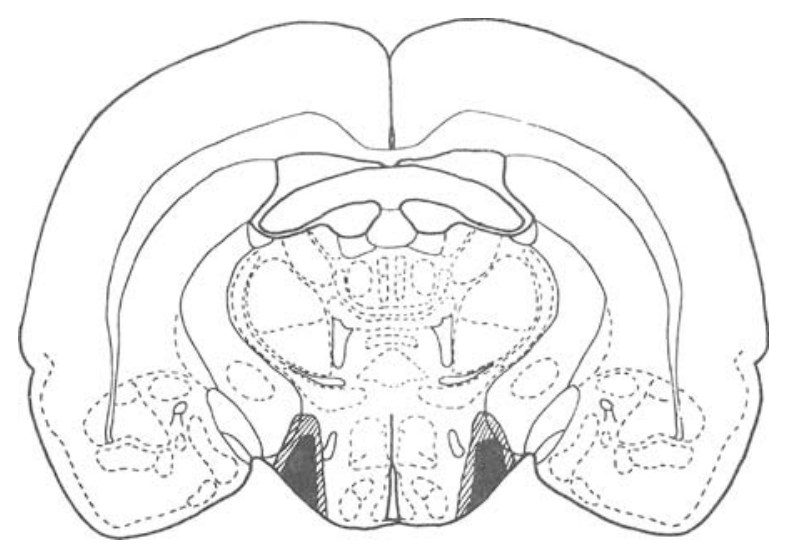

Figure 1. Diagrammatic representation of the rat brain through the hypothalamus (Pellegrino \& Cushman, 1967), showing the area of minimum damage (black) and the area of maximum damage (hatched) of the rats with LH lesions. 
Table 1

Number of Subjects Eating Placenta and Cookie Mash After LH Lesions, Non-LH Lesions, or a Sham Procedure, per Number of Animals Tested

\begin{tabular}{lcccc}
\hline \multirow{2}{*}{$\begin{array}{c}\text { Substance } \\
\text { Eaten }\end{array}$} & Sham & L-C & L-NP & L-P \\
\cline { 2 - 5 } & $8 / 8$ & $7 / 7$ & $0 / 4$ & $0 / 5$ \\
Placenta & $8 / 8$ & $7 / 7$ & $0 / 4$ & $0 / 5$ \\
Cookie Mash & $8 / 8$
\end{tabular}

Note-L-C = lesion-control group, $L-N P=$ lesion-nonpregnant group, L-P = lesion-pregnant group.

ence with placenta during parturition (Kristal, 1973), acquiring experience with placenta as a virgin by ingesting donor placenta presented in a dish does not prevent placentophagia from being eliminated by $\mathrm{LH}$ lesions. Therefore, it is not merely previous experience with a litter of placentas, nor is it the attractiveness of an attractive nonnovel substance, nor is it the possibility that in the previous study the experimental group was chosen from the proportion of females that are now known to be spontaneous placentophages, that accounts for the persistence of placentophagia in parturitionally experienced females with LH lesions.

\section{REFERENCES}

KRISTAL, M. B. Effects of lateral hypothalamic lesions on placentophagia in virgin, primiparous, and multiparous rats. Journal of Comparative and Physiological Psychology, 1973, 84, 53-62.

Kristal, M. B., \& Eleftheriou, B. E. Placentophagia in nonpregnant nulliparous mice: A genetic investigation. Behavioral Biology, 1975, 13, 113-119.

Kristal, M. B., \& GrABER, G. C. Placentophagia in nonpregnant rats: Influence of estrous cycle stage and birthplace. Physiology \& Behavior, 1976, 17, 599-605.

Kristal, M. B., \& Williams, C. L. The effects of strain, reproductive condition, and strain of placenta-donor, on placentophagia in nonpregnant mice. Physiological Psychology, 1973, 1, 354-356.

Pellegrino, L. J., \& Cushman, A. J. A stereotaxic atlas of the rat brain. New York: Appleton-Century-Crofts, 1967.

(Received for publication May 5, 1978.) 